\title{
Avaliação da Capacidade Inovativa na Indústria no Uso de Algas Sobre a Ótica Patentária Brasileira
}

\author{
Evaluation of Innovative Capacity in the Industry in the Use of Algae on \\ Brazilian Patentary Optical
}

\begin{abstract}
Resumo
O estudo das tecnologias que envolvem algas e suas aplicações na indústria são relevantes, pois as algas são importantes tanto ecologicamente quanto economicamente. Ecologicamente são importantes para a vida marinha e para a realização de fotossíntese, liberando a maior parte de oxigênio disponível; economicamente podem ser utilizadas em diversos segmentos da indústria. Com o objetivo de avaliar a capacidade inovativa das tecnologias envolvidas nesse cenário, foram utilizados dados de documentos patentários extraídos da base INPI-BR no qual foram selecionados 269 documentos de patentes, sendo 96 sobre obtenção de compostos a partir de algas no geral; 65 sobre tratamento contra algas no geral; 56 sobre utilização de algas no geral como parte de um produto e/ou processo; 51 sobre produção de algas no geral; e um sobre conservação de algas no geral. No entanto, verificouse que somente $11 \%$ desses documentos têm o segmento industrial revelado, com destaque para as indústrias farmacêutica, de alimentos e de bebidas, com sete documentos patentários cada.
\end{abstract}

Palavras-chave: Algas. Documentos Patentários. Mapeamento Tecnológico.

\begin{abstract}
The study of technologies involving algae and their applications in industry is relevant, since algae are important both ecologically and economically. Ecologically they are important for marine life and for photosynthesis, releasing most of the available oxygen; economically it can be used in several industry segments. In order to assess the innovative capacity of the technologies involved in this scenario, data from patent documents extracted from the INPI-BR database were used where 269 patent documents were selected, 96 on obtaining compounds from algae in general, 65 on treatment against algae in general, 56 on using algae in general as part of a product and / or process, 51 on algae production in general and 1 on algae conservation in general. However, it was found that only $11 \%$ of these documents have the industrial segment revealed, with emphasis on the pharmaceutical industries, and food and beverages with 7 patent documents each.
\end{abstract}

Keywords: Algae. Patent Documents. Technology Mapping.

Área Tecnológica: Prospecção Tecnológica. Outros. 


\section{Introdução}

O Brasil possui uma grande extensão aquática de grande riqueza, na qual se destacam as algas, os micro-organismos com grande importância ecológica e econômica. Uma vez que as algas além de serem grandes produtoras de oxigênio, servem de alimento as cadeias aquáticas e nosso, e, além disso, podem ser utilizadas como matéria prima em diversos segmentos da indústria. Neste artigo, a avaliação das tecnologias que envolvem algas e suas aplicações na indústria será realizada por meio da informação tecnológica contida nos documentos patentários e pelo mapeamento patentário.

\subsection{Contextualização das Algas}

Algas, por serem organismos clorofilados, podem fazer fotossíntese, sendo responsáveis por $90 \%$ da fotossíntese realizada na terra (SENAI, 2015). Não há valor taxonômico na terminologia "alga", já que elas representam organismos muito distintos entre si quanto à origem, composição química e à morfologia (LOURENÇO, 2006). Esses organismos são enquadrados em produtores primários, pois permitem a transformação de energia luminosa em energia química, gerando variadas moléculas, como polissacarídeos e lipídeos, que podem ser utilizados para diferentes fins. As algas são consideradas em três diferentes reinos: monera, protista e plantae, além de serem capazes de ocupar todos os meios que lhe ofereçam luz e umidade suficiente, seja de forma temporária ou permanente. Assim, elas podem ser encontradas em água doce, na água do mar, sobre solos úmidos e na neve (VIDOTTI; ROLLEMBERG, 2004), o que permite a esses seres uma ampla gama de meios para crescimento.

Historicamente, os povos asiáticos foram os primeiros relatados na literatura que aproveitaram as algas com alguma finalidade econômica, principalmente na forma de alimentos $e$ utilizando seus princípios ativos. Seu uso como consumo direto na alimentação humana é uma prática bastante antiga, com evidências de mais de 10.000 anos. No Japão, é relatado o uso de algas marinhas como fonte de ficocoloides no ano de 1968 (SILVA et al., 2016), quando iniciou a utilização de propriedades emulsificantes e estabilizantes do ágar de uma alga vermelha. Já no Brasil, por exemplo, a utilização de algas foi iniciada nas primeiras décadas do século XX, como fonte alimentícia, por colônias de imigrantes asiáticos. Todavia, seu uso no segmento industrial ocorreu somente após a Segunda Guerra Mundial (CARVALHO, 1987) com o propósito de contornar a escassez de produtos derivados de algas do mercado internacional, sendo a produção estabelecida apenas em datas posteriores à década de 1950, por falta de aparatos tecnológicos ou estudos biológicos para a comercialização de algas.

A partir das algas, podem ser obtidos diversos compostos, entre eles: metabolitos secundários, como nutrientes funcionais e compostos bioativos (FONSECA, 2016). Além disso, as algas podem ser utilizadas como parte de um produto e/ou matéria-prima de diversos processos, pois, entre suas habilidades, está a capacidade de sintetizar grande quantidade de lipídeos com elevada produtividade e taxa de crescimento durante todo o ano. Ainda, a partir das algas, podem ser gerados também biopolímeros, proteínas, polissacarídeos, pigmentos, entre outros (HU et al., 2008). Por esses motivos, as algas se tornaram interessantes para diversas indústrias, entre elas: alimentar, farmacêutica, biodiesel e biossensores. 
No entanto, o crescimento em excesso de algas, por exemplo, o Harmful Algal Bloom (HAB), que vem ocorrendo no mundo todo, é prejudicial tanto ao meio ambiente, pois torna a água e toda a vida marinha inviável, quanto economicamente, por exemplo, no setor de saúde pública, turismo e indústria de produtos marinhos (NOAA, 2015).

Observada a diversidade estrutural e tecnológica do emprego de algas em diferentes segmentos da indústria, verifica-se a necessidade de se realizar uma avaliação macro do panorama das principais tecnologias envolvidas. Uma das formas de se avaliar a evolução tecnológica é por meio das informações contidas nos documentos patentários, foco deste artigo.

\subsection{Documentos Patentários como Fonte de Informação Inovativa}

Nesse cenário, os documentos patentários surgem como uma excelente fonte de informação tecnológica, uma vez que, além de divulgarem em seu corpo textual informações técnicas em escala mundial sobre novas invenções, esses documentos não são de exclusiva utilização por parte de cientistas ou técnicos nas indústrias, sendo utilizados em processos corporativos ou marketing, em estudos de análise de risco e planejamento estratégico e nas atividades de pesquisa e desenvolvimento.

Atualmente, são desenvolvidos métodos para extrair as expertises tecnológicas das bases de dados, como: jornais e internet. Nesse contexto, tem-se por objetivo capturar e disseminar a informação tecnológica necessária para o planejamento estratégico, possibilitando a tomada de decisões. Destaca-se que essa nova inteligência possibilita que as indústrias identifiquem oportunidades tecnológicas e abordem praticamente o que pode afetar o crescimento futuro e a sobrevivência do seu negócio (BUZZANGA, 2008).

Quanto à sua vigência jurídica, os documentos patentários podem ser classificados como: (i) documentos de pedidos de patente; e (ii) documentos de patentes concedidas (ou simplesmente - chamados de Patentes). O primeiro conjunto de documentos se refere a documentos que apresentam pela primeira vez a invenção a um escritório de patentes, enquanto ao segundo conceito imputa-se o entendimento de um título outorgado pelo Estado aos inventores ou autores ou outras pessoas físicas ou jurídicas detentoras de direitos sobre a criação do invento, durante o período de sua vigência (INPI, 2018).

Os documentos patentários possuem como pressupostos necessários para a patenteabilidade: a descrição técnica detalhada da invenção, a novidade, a atividade inventiva e a aplicação industrial. E, de acordo com dados da Organização Mundial da Propriedade Intelectual (OMPI), cerca de $70 \%$ de toda informação está na forma de patentes, sendo que, em mais de $80 \%$ dos casos, seu conteúdo não será publicado em qualquer outra fonte de informação (WIPO, 2018a). Em 2007, o acervo mundial registrou mais de 50 milhões de documentos, com um crescimento anual da ordem de um milhão e 500 mil novos documentos patentários (WIPO, 2018a).

Os documentos de patentes são classificados na maioria de escritórios de patentes, de acordo com um sistema único de codificação: a Classificação Internacional de Patentes (CIP $)^{1}$, conjunto de signos que relacionam ou agrupam as patentes de acordo com as áreas técnicas a que pertencem. A CIP é um instrumento que possibilita a organização dos documentos de pa-

\footnotetext{
${ }^{1}$ A Classificação Internacional de Patentes (CIP) é um sistema hierárquico em que todos os setores tecnológicos são divididos em um número de seções, classes, subclasses e grupos. Esse sistema é essencial para recuperar os documentos de patentes para a avaliação da novidade e da inventiva de uma invenção, ou para determinar o estado da arte em um campo específico da tecnologia, o termo foi definido após o Acordo de Estrasburgo de 1971 que permitiu estabelecer uma classificação comum para patentes, modelos de utilidade e títulos semelhantes.
} 
tente, usado com a finalidade de facilitar o acesso às informações tecnológicas e legais contidas neles. As versões mais atuais da CIP podem ser acessadas no site da WIPO² (WIPO, 2018b).

Com base no que foi exposto, este artigo tem como objetivo, por meio do monitoramento de documentos de patentes depositados no Brasil, realizar o mapeamento patentário das tecnologias que envolvem algas e suas aplicações na indústria. A intenção é possibilitar ao público a verificação na prática de como as expertises adquiridas, com relação às informações técnicas contidas em documentos patentários, podem agregar conhecimento sob o ponto de vista das tecnologias que envolvem algas e suas aplicações na indústria.

\section{Metodologia}

Para avaliar o emprego de algas na indústria por meio de documentos patentários, foi utilizado o mapeamento patentário por atividade (PORTER, 1991). A partir dos documentos obtidos, foram extraídos e tabulados os dados da base INPI-BR ${ }^{3}$, na qual se buscou recuperar todos os pedidos de patentes sobre o tema algas que foram depositados no Brasil.

A metodologia de pesquisa usada para recuperação de documentos patentários foi a busca por palavras-chave: alga, microalga e macroalga (incluindo o plural) no título e no resumo; e, para tanto, não foi utilizado limite temporal. Destaca-se que do resultado dessa busca, foram removidos os duplicados ${ }^{4}$. A seguir foi realizada a leitura dos resumos dos documentos patentários, selecionando, assim, os documentos referentes a algas e sua aplicação industrial, excluindo os demais documentos que não se referiam ao tema. Na sequência, foi realizada uma análise quantitativa dos documentos patentários referentes a algas e suas principais aplicações na indústria, bem como os escritórios em que esses documentos patentários foram depositados e seus depositantes.

\section{Resultados e Discussão}

Foram extraídos e tratados 422 documentos patentários da busca realizada na base INPI-BR, utilizando palavras-chave (descritas na metodologia) e sem limitação temporal. Após retirar os documentos duplicados, restaram 377 documentos patentários. Sendo que após a leitura dos resumos, foram extraídos 269 documentos patentários relacionados ao tema algas e sua aplicação na indústria.

Com a leitura e a análise dos resumos dos documentos patentários, os documentos foram subdivididos em: obtenção de compostos a partir de algas no geral (96 documentos patentários); tratamento contra algas no geral (65 documentos patentários); utilização de algas no geral como parte de um produto e/ou processo (56 documentos patentários); produção de algas no geral (51 documentos patentários); e conservação de algas no geral (1 documento patentário).

A partir dos documentos patentários, foi detectado à qual segmento industrial a invenção pertencia. Somente $11 \%$ dos documentos patentários têm o segmento industrial definido, que são: farmacêutico (7 documentos patentários), alimentício (5 documentos patentários), bio-

\footnotetext{
${ }^{2}$ As versões mais atuais da CIP podem ser acessadas no site da WIPO ou diretamente por este site: http://ipc.inpi.gov.br/ipcpub/\#refresh=page.

${ }^{3}$ Esta base de dados só contém documentos patentários depositados no Brasil.

${ }^{4}$ A busca foi realizada por meio de uma palavra por vez.
} 
combustível (3 documentos patentários), agroindústria ( 2 documentos patentários), bebidas ( 2 documentos patentários), bioenergia/biofertlizante (1 documento patentário), composição de fibras com biocidas (1 documento patentário), cosmético (1 documento patentário), limpeza industrial (1 documento patentário), para detecção de inseticidas organofosforados (1 documento patentário), produção de embalagem (1 documento patentário), tintas (1 documento patentário), tratamento de água (1 documento patentário) e diversos segmentos da indústria. Notou-se um destaque para a indústria farmacêutica, de alimentos e de bebidas, com $23 \%$ cada.

A seguir, será apresentada uma análise quantitativa dos documentos patentários referentes a algas e suas principais aplicações na indústria.

Gráfico 1 - Evolução temporal dos documentos patentários depositados relacionados a algas e suas aplicações na indústria

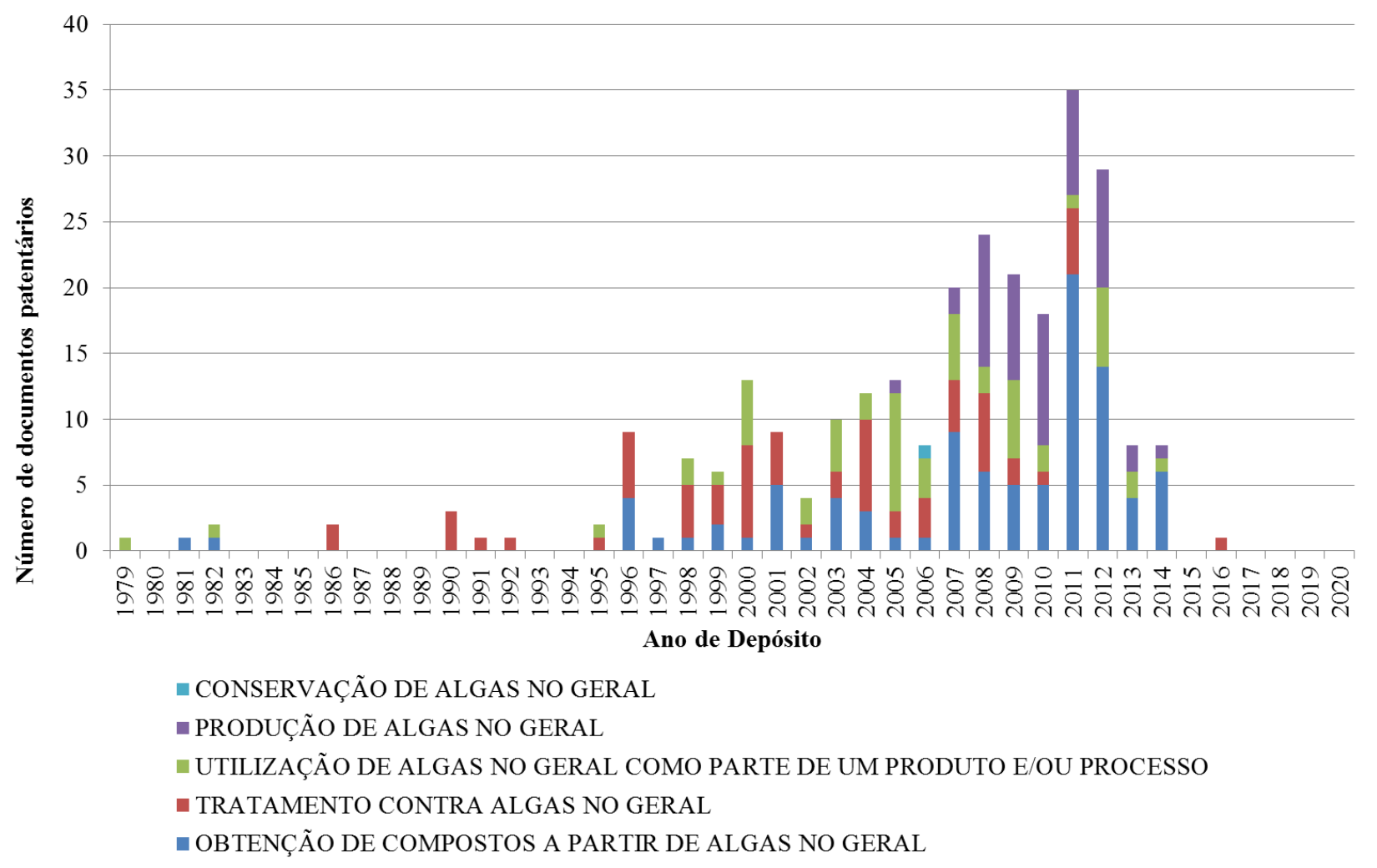

Fonte: Elaborado pelos autores deste artigo a partir de base patentária INPI-BR (2020)

Nota-se que, no Gráfico 1, existe um comportamento concentrado dos depósitos entre 1996 e 2015 com pico entre 2007 e 2012 (mostrado em detalhe no Gráfico 2). Observa-se também que os documentos patentários relacionados: ao tratamento contra algas no geral e a obtenção de compostos a partir de algas no geral apresentam dois pedidos entre 1981/1982 depois se apresentam distribuídos entre 1996 e 2014, com pico em 2001/2012; ao tratamento contra algas no geral estão distribuídos entre 1986 e 2016; a utilização de algas no geral como parte de um produto e/ou processo apresenta dois pedidos um em 1979 e outro em 1982 depois estão distribuídos entre 1995 e 2014, com pico em 2005; a produção de algas no geral está distribuída entre 2005 e 2014, concentrados entre 2008 e 2012; e o único pedido sobre conservação de algas no geral ocorreu em 2006. 
O crescimento do número de documentos patentários a partir de 2007 está relacionado ao desenvolvimento tecnológico para a produção de biodiesel de terceira geração, ou seja, produto que é produzido a partir de microalgas, corroborando com o que foi apresentado por Rocha et al. (2012). Já diversas reportagens da Ubrabio (2012; 2013) também corroboram com esse cenário de desenvolvimento tecnológico para a produção de biodiesel a partir de algas, noticiando desenvolvimento de inventores nacionais e da Universidade de São Paulo (USP).

Com relação à falta de depósitos entre 2015 e 2017, isso pode ter ocorrido devido às pesquisas de produção de biodiesel e pelo fato de as algas estarem paradas nesse período, o que corrobora com a notícia de retomada dessas pesquisas em 2015, mas que só gerariam documentos patentários futuros (UBRABIO, 2015).

Gráfico 2 - Evolução temporal dos documentos patentários depositados relacionados a algas e suas aplicações na indústria no período do pico (entre 2007 e 2012)

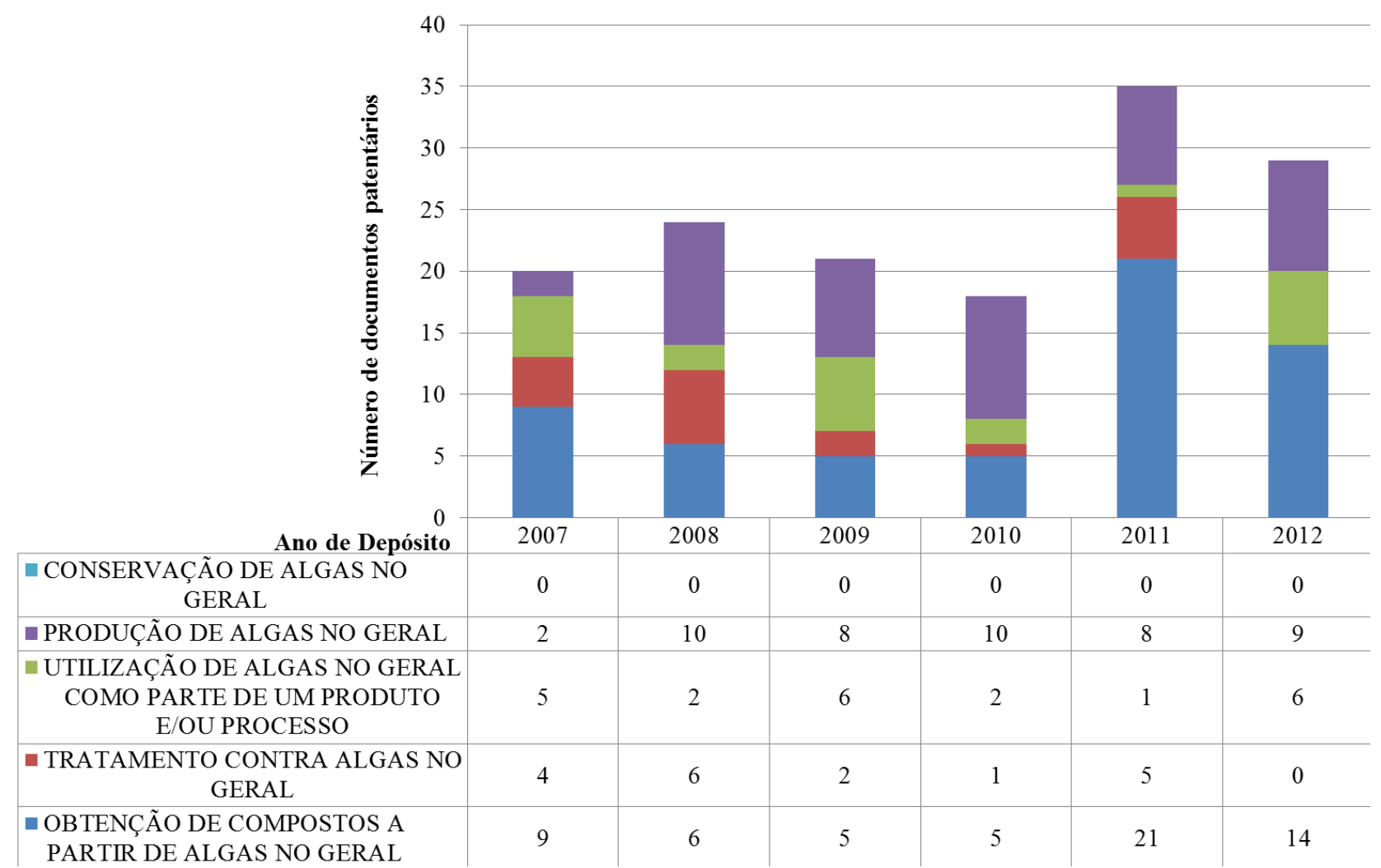

Fonte: Elaborado pelos autores deste artigo a partir de base patentária INPI-BR (2020)

O Gráfico 2 mostra com detalhes o pico de crescimento dos documentos patentários depositados relacionados a algas e suas principais aplicações na indústria entre os anos de 2007 e 2012. O grande pico ocorreu em 2011, com 35 documentos patentários, com ênfase nos depósitos de documentos de obtenção de compostos a partir de algas no geral (21 documentos patentários) e de produção de algas no geral (8 documentos patentários). 
Gráfico 3 - Principais origens dos documentos patentários relacionados a algas e suas aplicações na indústria

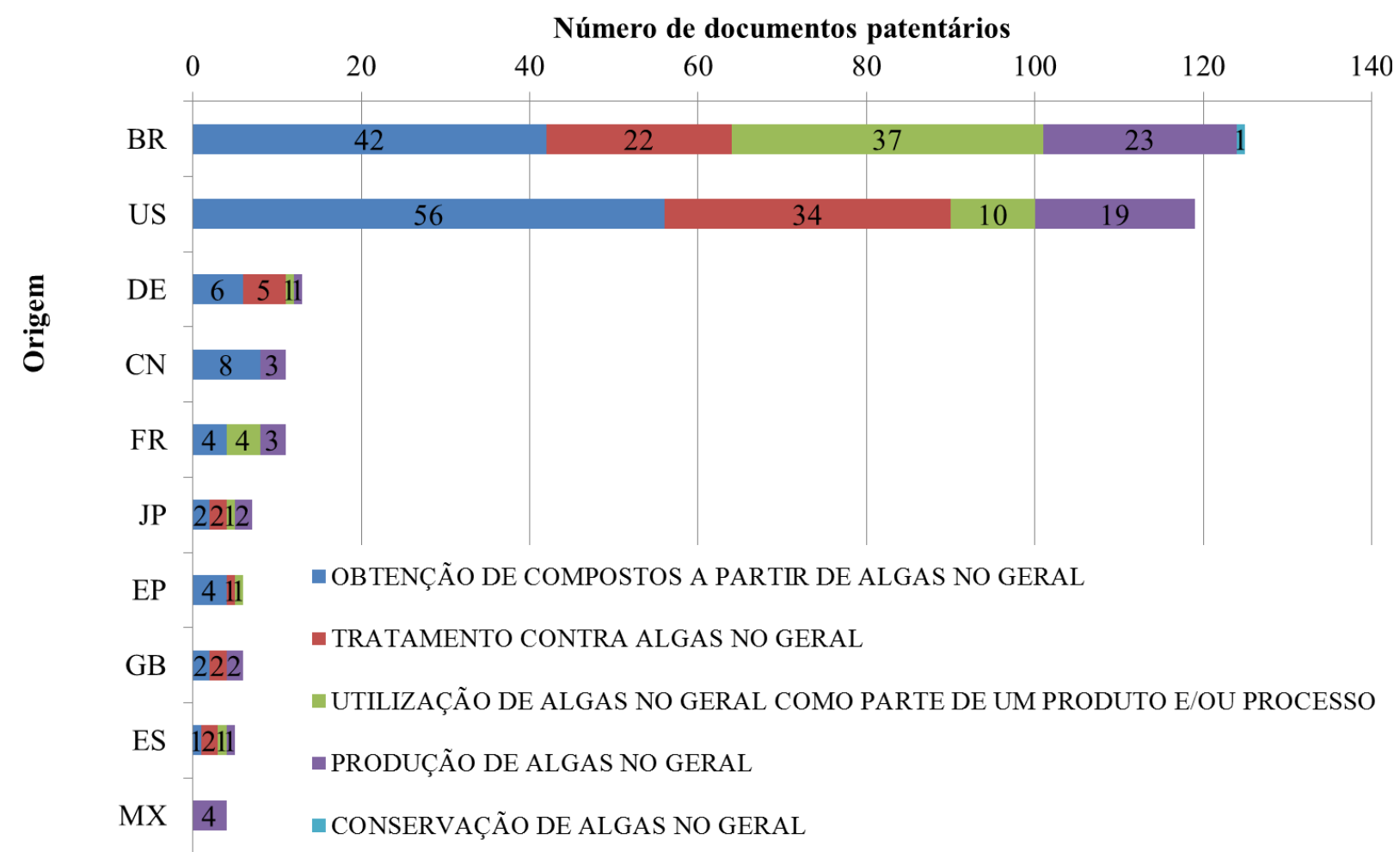

Fonte: Elaborado pelos autores deste artigo a partir de base patentária INPI-BR (2020)

O Gráfico 3 mostra as 10 principais origens dos documentos patentários relacionados a algas e suas principais aplicações na indústria (como por exemplo: tratamento de efluentes líquidos e produção de biogás, fertilizante sólido orgânico, organomineral e/ou fonte de nutrientes para plantas e para obtenção de água reutilizável em sistemas agroindustriais). Nele pode-se observar que a principal origem dos documentos patentários é dividida entre o Brasil (38\%) e os Estados Unidos (37\%), com 244 depósitos , no total (74,8\%). A origem dos depósitos indica que, nos países abrangidos por esses escritórios, o mercado para a pesquisa e uso das algas no segmento industrial é relevante.

Com relação aos Estados Unidos, de acordo com Rocha et al. (2012), nota-se que este é o país de onde se origina a maioria dos documentos patentários relativos à produção de biodiesel de microalgas (terceira geração). E o Gráfico 3 mostra que os Estados Unidos também têm interesse em proteger suas invenções no Brasil.

Tanto o Brasil quanto os Estados Unidos se destacam na obtenção de compostos a partir de algas no geral, no entanto, o segundo maior destaque do Brasil é a utilização de algas no geral como parte de um produto e/ou processo, e o terceiro está equilibrado entre produção de algas no geral e tratamento de algas no geral; já nos Estados Unidos, o segundo maior destaque é o tratamento de algas no geral e o terceiro é a produção de algas no geral. 
Gráfico 4 - Principais depositantes dos documentos patentários relacionados a algas e suas aplicações na indústria

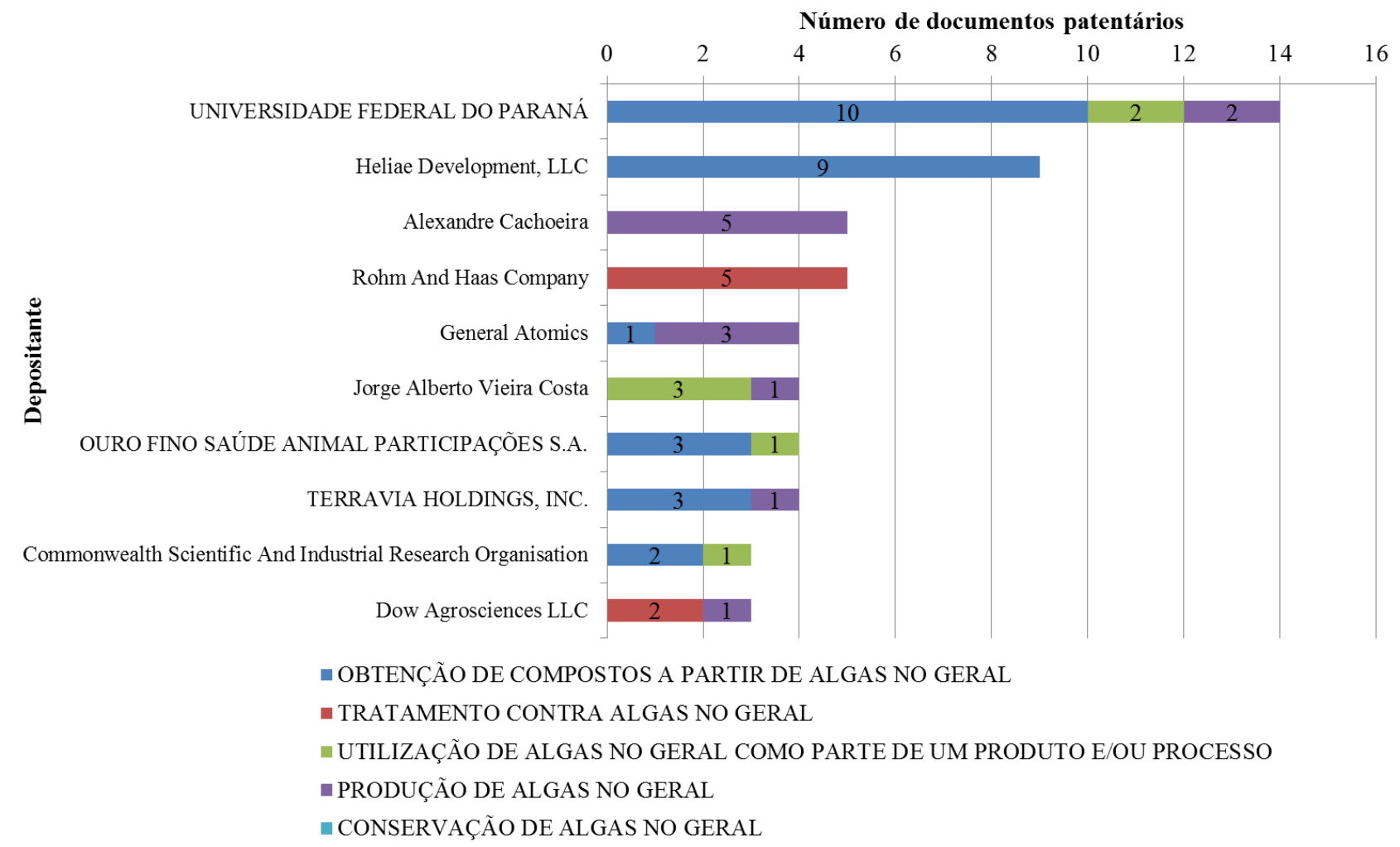

Fonte: Elaborado pelos autores deste artigo a partir de base patentária INPI-BR (2018)

Com relação aos depositantes ${ }^{5}$, conforme observado no Gráfico 4, eles estão distribuídos de forma não concentrada: 194 depositantes têm somente um documento patentário depositado; 25 depositantes têm dois documentos patentários depositados; cinco depositantes têm três documentos patentários depositados; quatro depositantes têm quatro documentos patentários depositados; dois depositantes têm cinco documentos patentários depositados; um depositante tem nove documentos patentários depositados e um depositante tem 14 documentos patentários depositados.

Entre os depositantes, destacam-se: (a) Universidade Federal do Paraná - universidade brasileira (com 10 depósitos sobre obtenção de compostos a partir de algas (por exemplo: polissacarídeos sulfatados, gel de polissacarídeos e gel termoestável de polissacarídeos complexados com íons boratos, sódio e/ou cálcio e extrato de microalgas) no geral; dois depósitos sobre utilização de algas no geral como parte de um produto e/ou processo (por exemplo: (1) processo de uso industrial de resíduos orgânicos líquidos, como: agroindustriais e agropecuários para fabricação de biogás como metano, fertilizante sólido orgânico, organomineral e/ou fonte de nutrientes para plantas e para obtenção de água reutilizável em sistemas agroindustriais; (2) tratamento de efluentes líquidos e emissões, chamados de poluentes, por meio do cultivo de microalgas e/ou cianobactérias em um fotobiorreator concomitantemente com a geração de energia proveniente da biomassa final do processo) e dois depósitos sobre produção de algas no geral); e (b) Heliae Dev LLC - empresa americana (com nove depósitos sobre obtenção de compostos a partir de algas no geral). 


\section{Considerações Finais}

Com a elaboração deste mapeamento patentário, demonstrou-se que um processo de gestão e monitoramento tecnológico por documentos patentários pode ser bem oportuno para, por exemplo, tecnologias que envolvam o uso de algas e suas aplicações na indústria, devido ao potencial e ao conteúdo de informação estratégica contidos nesses documentos.

O mapeamento da evolução de tecnologias mostra a evolução histórica da produção de patentes de um dado tema/assunto ao longo dos anos. Por isso, é possível concluir que o número de depósitos sobre as algas e suas aplicações na indústria oscila no intervalo entre 1996 e 2015 com pico entre 2007 e 2012. Como não foram obtidos documentos patentários referentes a algas e suas aplicações na indústria após aproximadamente 2015, apesar de a busca ter sido feita sem limite temporal, conclui-se que o desenvolvimento de tecnologias que envolvem algas a partir de 2007 estão relacionadas com a produção de biodiesel de terceira geração. Com relação à falta de documentos a partir de 2015, ela está relacionada com a desaceleração do setor que foi retomado em 2015, o que geraria documentos patentários futuros, ou também pode ser que o que esteja sendo desenvolvido a partir de 2015 não seja passível de patenteamento.

Os principais assuntos abordados nos documentos patentários analisados são: obtenção de compostos a partir de algas no geral (36\%) - principalmente biodiesel, polissacarídeos e extratos de microalgas, tratamento contra algas no geral (24\%); utilização de algas no geral como parte de um produto e/ou processo $(21 \%)$ - principalmente no tratamento de efluentes e produção de biogás, fertilizantes e água reutilizável e produção de algas no geral (19\%).

Com relação ao segmento industrial identificado nesses documentos patentários, destaca-se que somente $11 \%$ dos documentos patentários têm o segmento industrial definido, com destaque para as indústrias: farmacêutica, de alimentos e de bebidas, com $23 \%$ cada.

O Gráfico 3 mostra as 10 principais origens dos documentos patentários relacionados a algas e suas principais aplicações na indústria. Nele, pode-se observar que a principal origem dos documentos patentários é dividida entre o Brasil (38\%) e os Estados Unidos (37\%), com 244 depósitos no total $(74,8 \%)$. A origem dos depósitos indica que, nos países abrangidos por esses escritórios, o mercado para a pesquisa e o uso das algas no segmento industrial são relevantes. $\mathrm{O}$ que mostra que mostra que os Estados Unidos, de onde se originam a maioria dos documentos patentários sobre biodiesel a partir de algas no mundo, também têm interesse no mercado brasileiro, indicando que o mercado brasileiro é competitivo nesse setor.

Com relação aos depositantes, estes apresentam comportamento distribuído, com destaque para: (a) Universidade Federal do Paraná - universidade brasileira (com 14 depósitos); e (b) Heliae Dev LLC - empresa americana (com nove depósitos).

A presente pesquisa buscou contribuir para o avanço do conhecimento sobre algas e suas aplicações na indústria sobre a ótica patentária. Os resultados obtidos permitiram que o objetivo desta pesquisa fosse alcançado.

Diante do exposto, tem-se como sugestões para trabalhos futuros: (1) limitar a tecnologia somente para microalgas; (2) limitar a tecnologia somente para biodiesel; e (3) ampliar o estudo retirando a limitação no território brasileiro e buscando em outras bases. 


\section{Referências}

BUZZANGA, J. Using Technology intelligence for R\&D, 3 set. 2008. Disponível em: http://www. industryweek.com/articles/using_technology_intelligence_for_rd_17162.aspx. Acesso em: 2 jan. 2018.

CARVALHO, F. A. F. Produção, comercialização e industrialização de algas marinhas na América do Sul. Arquivos de Ciências do Mar, [s.l.], v. 26, n. 1-2, p. 51-58. 1987.

FONSECA, J. A. Aplicação de Algas na Indústria Alimentar e Farmacêutica. 2016. 75f. Projeto (Pós-Graduação) - Universidade Fernando Pessoa, Porto, 2016.

HU, Q. et al. Microalgal triacylglycerols as feedstocks for biofuel production: perspectives and advances. Plant. J., [s.l.], v. 54, n. 4, p. 621-39, 2008.

INPI - INSTITUTO NACIONAL DA PROPRIEDADE INDUSTRIAL. 2018. Disponível em: http:// www.inpi.gov.br. Acesso em: 2 jan. 2018.

LOURENÇO, S. O. Cultivo de microalgas marinhas: princípios e aplicações. São Carlos, SP: Ed. Rima, 2006.

NOAA - NATIONAL OCEANIC AND ATMOSPHERIC ADMINISTRATION. Satellites See Red, Blue and Green: Monitoring Harmful Algal Blooms from Space. 11 dez. 2015. Disponível em: https://www.nesdis.noaa.gov/content/satellites-see-red-blue-and-green-monitoring-harmful-algalblooms-space. Acesso em: 2 jan. 2018.

PORTER, A. L. Forecasting and management of technology. Estados Unidos: Wiley Series in Engineering and Technology Management, 1991. p. 306-307.

ROCHA, A. M. et al. Biodiesel production from microalgae: a mapping of articles and patents. In: GORDON, R.; SECKBACH, J. (ed.). The science of algal fuels: phycology, geology, biophotonics, genomics and nanotechnology. Springer: [s.n.], 2012. p. 283-303.

SENAI - SERVIÇO NACIONAL DE APRENDIZAGEM INDUSTRIAL. Microbiologia aplicada a processos industriais. São Paulo: Senai-SP, 2015.

SILVA, F. N. et al. VI Botânica no Inverno 2016. São Paulo: Instituto de Biociências da Universidade de São Paulo, Departamento de Botânica, 2016. 223p.

UBRABIO. Brasileiras estudam produção de biodiesel com cianobactérias, 20 jan. 2012. Disponível em: https://ubrabio.com.br/2012/01/20/brasileiras-estudam-producao-de-biodiesel-comcianobacterias/. Acesso em: 2 jan. 2018.

UBRABIO. USP tenta transformar algas em biocombustível, 4 nov. 2013. Disponível em: https:// ubrabio.com.br/2013/11/04/usp-tenta-transformar-algas-em-biocombustivel/. Acesso em: 2 jan. 2018.

UBRABIO. Aumentam pesquisas para produção de biodiesel a partir de microalgas, 9 out. 2015. Disponível em: https://ubrabio.com.br/2015/10/09/aumentam-pesquisas-para-producao-debiodiesel-a-partir-de-microalgas/. Acesso em: 2 jan. 2018.

VIDOTTI, Eliane Cristina; ROLLEMBERG, M. C. do E. Algas: da economia nos ambientes aquáticos à biorremediação e à química analítica. Química Nova, [s.1.], v. 27, n. 1, p. 139-145, 2004. 
WIPO - WORLD INTELLECTUAL PROPERTY ORGANIZATION. 2018a. Disponível em: http:// www.wipo.int. Acesso em: 2 jan. 2018.

WIPO - WORLD INTELLECTUAL PROPERTY ORGANIZATION. Reformed IPC. 2018b.

Disponível em: http://www.wipo.int/ipcpub/\#lang=en\&refresh=page. Acesso em: 2 jan. 2018.

\section{Sobre os Autores}

\section{Marcello Carvalho dos Reis}

E-mail: mcarv.reis@gmail.com

Mestre em Metrologia pela Pontifícia Universidade Católica do Rio de Janeiro.

Endereço profissional: Rua Joaquim Nabuco, n. 3.370, Bairro Dionísio Torres, Fortaleza, CE. CEP: 60125-151.

\section{Rafaelly Rios dos Santos}

E-mail: rafaellyrios.adv@gmail.com

Bacharel em Direito pela Universidade de Fortaleza.

Endereço profissional: Rua Joaquim Nabuco, n. 3.370, Bairro Dionísio Torres, Fortaleza, CE. CEP: 60125-151.

\section{Maria Elisa Marciano Martinez}

E-mail: melisamm2501@gmail.com

Mestre em Engenharia Química pela Universidade de São Paulo.

Endereço profissional: Rua Tabapuã, n. 41, 4 andar, Bairro Itaim-Bibi, São Paulo, SP. CEP: 04533-010.

\section{Marcelo Farid Pereira}

E-mail: faridmarcelo@gmail.com

Doutor em Engenharia de Produção pela Universidade Federal de Santa Catarina.

Endereço profissional: Universidade Estadual de Maringá, Centro de Estudos Socioeconômicos, Departamento de Economia, Zona 7, Maringá, PR. CEP: 87020-900. 